\title{
Obstructive Sleep Apnea in General Surgery Patients: Is Screening Required Preoperatively?
}

\author{
Osama Ahmed*, Zahid Habib, Sheeraz Ur Rahman, Arshad Beg, Maira Shoaib, Asma Hirani, \\ Abeer Hamidani
}

Department of General Surgery, Liaquat National Hospital, Karachi, Pakistan.

\begin{abstract}
Aim: To screen cases who are at high risk and low risk for obstructive sleep apnea in general surgery patients.
Materials \& Methods: It is a cross-sectional study. It was done in Liaquat National Hospital from January 2019 to June 2019. After institutional approval, 335 patients were included in this study, who presented to general surgery OPD. STOP-BANG questionnaire was used to screen cases who are at high risk and low risk for obstructive sleep apnea in general surgery patients.

Results: 335 patients were screened and $38.5 \%$ of individuals in population had age of more than 50 years. In this population $149(44.5 \%)$ of patients were male. Out of 335 patients, 135(40.3\%) of them were found to have high risk of obstructive sleep apnea while the remaining $199(59.7 \%)$ were classified in low risk group. All of the parameters of STOP-bang questionnaire including age $(\mathrm{p}<0.001)$, gender $(\mathrm{p}=0.026)$, BMI ( $p<0.001)$, snoring $(p<0.001)$, tiredness $(p<0.001)$, sleep apnea $(p=0.001)$, diastolic blood pressure $(p<0.001)$ and neck circumference $(\mathrm{p}<0.001)$ were significantly different between high risk and low risk patients.
\end{abstract}

Conclusion: This study can provide a catalyst for more meticulous screening for OSA preoperatively to diagnose high risk group.

Keywords: Sleep Apnea, Obstructive, Care, Preoperative, Surgery, General, Operative Procedures.

\section{INTRODUCTION}

Sleep apnea is common condition. In general population, it has an incidence of $2-26 \%$ [1] and involving $14 \%$ of men and $5 \%$ of women [2]. The prevalence in bariatric surgical population is found to be as high as 70\% [3] but in other surgeries it varies but one study found it to be $55 \%$ [4]. There is a significant study done in Pakistan which showed $14.2 \%$ had mild severity while $50.7 \%$ had severe OSA and they only performed polysomnography test of everyone who presented to their sleep lab [5] but we screened them with STOP-BANG Questionnaire and only in elective surgical population to group them into high risk and low risk.

Periodic reduction or cessation of breathing during sleep are characteristic features of sleep apnea. Obstructive sleep apnea (OSA) and central sleep apnea (CSA) are the main types of sleep apnea with third type being called mixed sleep apnea which is a combination of both central and obstructive types.

Sleep apnea symptoms include, sleepiness and tiredness during daytime, memory problems, headaches, poor focus and concentration, anxiety, difficulty in performing work duties and irritability. Obstructive sleep apnea can also be associated with comorbidities like hypertension, cardiovascular disease and gastroesophageal reflux [6]. OSA in surgical population causes adverse outcomes as complications which include cardiac complications (acute myocardial infarction and cardiac arrest), septicemia, septic shock, stroke, respiratory failure,

*Address correspondence to this author at the Department of General Surgery, Liaquat National Hospital, Karachi, Pakistan.

Email: osamaahmed991@gmail.com and need for reintubation or mechanical ventilation, and pulmonary embolism, deep venous thrombosis, pneumonia and postoperative anemia [7] and dreadful complications like ischemic heart disease, heart failure, pulmonary hypertension and irregular heart rate have shown associations with sleep apnea [8-12].

Sleep apnea prevention includes preventive measures against medical conditions which predispose to sleep apnea. Again, proper sleep hygiene, exercise, weight loss, avoidance of drug use and smoking cessation are the key steps which can help in prevention of sleep apnea. Populations of high risk of obstructive sleep apnea remain undiagnosed because of reluctance of people to get screened and among healthcare professionals, lack of information or no access to diagnostic tools are the reasons for low rates $[13,14]$.

Our aim is to determine the high risk of OSA in preoperative patients in tertiary hospital in Pakistan. The study rationale is early identification of high risk of OSA in previously undiagnosed patients using questionnaire can lead to appropriate management.

\section{MATERIALS AND METHODS}

This cross-sectional study was done in outpatient clinic of general surgery in Liaquat National Hospital after acquiring approval from Institutional Review Board. The study was conducted in duration of 6 months from January 2019 to June 2019. Patients included in this study are all those patients admitted in general surgery department undergoing preopera- 
tive evaluation and does not fit in exclusion criteria. Our exclusion criteria is all those patients with secondary causes of obstructive sleep apnea are excluded from this study, for example, a deviated nasal septum, nasal congestion, enlarged tonsils, disrupted airway passages caused by facial trauma, some sedative medications, cerebrovascular diseases (such as stroke, leading to airway muscles weakness), and smoking. Inclusion criteria is all preoperative patients not coming under exclusion criteria. Sample size was taken using the consecutive sampling technique.

All the new patients admitted consecutively and they themselves completed the STOP questionnaire and BANG was calculated by trained assessors. Patient's demographics were identified after reviewing electronic medical records. Neck circumference was measured using measuring tape in centimeters. BMI was taken more than $35 \mathrm{~kg} / \mathrm{m}^{2}$ which is class 2 obesity according to WHO classification [15].

Data was analyzed using statistical package SPSS version 25. Frequencies and percentages were computed for categorical variables whereas mean \pm standard deviation was computed to summarize quantitative variables. Chi-square test was applied to compare patients' characteristics among high and low risk group of OSA. A P-value $<0.05$ considered statistically significant meaning that there is a significant evidence proving association between groups.

STOP-BANG questionnaire [16] was used to screen and classify high risk and low risk individuals. The questionnaire has total of 8 questions and if the individual score $\geq 3$ then its high risk and if scored $\leq 2$ then it is low risk in Fig. (1).

\begin{tabular}{|c|}
\hline STOP-Bang Questionnaire \\
\hline $\begin{array}{l}\text { 1. Snoring: Does one snore loud enough to be heard in adjacent } \\
\text { room? }\end{array}$ \\
\hline $\begin{array}{l}\text { 2. Tired: Does one often feel daytime sleepiness, fatigued or } \\
\text { tiredness? }\end{array}$ \\
\hline $\begin{array}{l}\text { 3. Observed apneas: Has someone seen you having difficulty in } \\
\text { breathing during sleep?............................... Yes/No }\end{array}$ \\
\hline $\begin{array}{l}\text { 4. Blood pressure: Does one have high blood pressure or taking } \\
\text { medications for it? }\end{array}$ \\
\hline 5. Body mass index $(\mathrm{BMI}):>35 \mathrm{~kg} / \mathrm{m} ? \ldots \ldots \ldots \ldots . .$. Yes $/$ No \\
\hline 6. Age: 50 years old or older? Yes / No \\
\hline 7. Neck circumference: more than $40 \mathrm{~cm}$ ?........Yes/ No \\
\hline 8. Gender: is your sex male? ................................ Yes/ No \\
\hline $\begin{array}{l}\text { If your answers are Yes to }=\text { or }>3 \text { questions then there is High risk } \\
\text { of obstructive sleep apnea }\end{array}$ \\
\hline $\begin{array}{l}\text { If your answers are Yes to }<3 \text { questions then there is Low risk of } \\
\text { obstructive sleep apnea }\end{array}$ \\
\hline
\end{tabular}

Fig. (1). STOP-Bang Questionnaire to Stratify Low and High Risk Group.

\section{RESULTS}

The detailed descriptive statistics of patients is presented in Table 1. 335 patients were presented in general surgery OPD and were added on preoperative list. In this population $44.5 \%$ of patients were male while frequency of females was higher than males. $38.5 \%$ of patients were elderly having age of more than 50 years. Most of the patients had BMI $<35 \mathrm{Kg} / \mathrm{m}^{2}$. There were $26.6 \%$ cases of loud snoring, $46.9 \%$ had day time tiredness and $10.4 \%$ had difficulty in breathing during sleep. Some of them had high diastolic BP while $71 \%$ had low diastolic BP. The neck circumference $\geq 40 \mathrm{~cm}$ was found in $19.7 \%$ cases in Table $\mathbf{1}$.

Table. 1. Descriptive Statistics of Population under Study.

\begin{tabular}{|l|c|}
\hline \multicolumn{2}{|l|}{ STOP-BANG } \\
\hline Age & $206(61.5)$ \\
\hline$<50$ years & $129(38.5)$ \\
\hline$\geq 50$ years & $149(44.5)$ \\
\hline Gender & $186(55.5)$ \\
\hline Male & \\
\hline Female & $308(91.9)$ \\
\hline Body Mass Index(BMI) & $27(8.1)$ \\
\hline$<35 \mathrm{Kg} / \mathrm{m}^{2}$ & \\
\hline$\geq 35 \mathrm{Kg} / \mathrm{m}^{2}$ & $89(26.6)$ \\
\hline Snoring & $246(73.4)$ \\
\hline Yes & \\
\hline No & $157(46.9)$ \\
\hline Tired & $178(53.1)$ \\
\hline Yes & \\
\hline No & $35(10.4)$ \\
\hline Sleep Apnea & $300(89.6)$ \\
\hline Yes & $238(71)$ \\
\hline No & $97(29)$ \\
\hline Diastolic Bp & $135(40.3)$ \\
\hline$<90 \mathrm{mmHg}$ & $199(59.4)$ \\
\hline$\geq 90 \mathrm{mmHg}$ & \\
\hline Neck Circumference & \\
\hline$<40 \mathrm{~cm}$ & \\
\hline$\geq 40 \mathrm{~cm}$ & \\
\hline Risk & \\
\hline High & \\
\hline Low & \\
\hline \multicolumn{2}{|c|}{} \\
\hline
\end{tabular}

Out of these $40.3 \%$ of patients were found to have high risk of obstructive sleep apnea while the remaining $59.7 \%$ were classified in low risk group. 
Summary of total procedures performed in both low and high risk groups is presented in Fig. (2). Among all patients, hepatobiliary surgery $(28.7 \%)$ is the commonest performed procedure followed by colorectal surgery $(25.1 \%)$, hernia repair $(11.9 \%)$, breast and endocrine surgery $(10.4 \%)$, miscellaneous (6\%), amputation (5.7\%), abscess I \& D (4.2\%), vascular surgery $(3.6 \%)$, perinatal surgery $(3.6 \%)$, upper GI surgery $(0.9 \%)$.

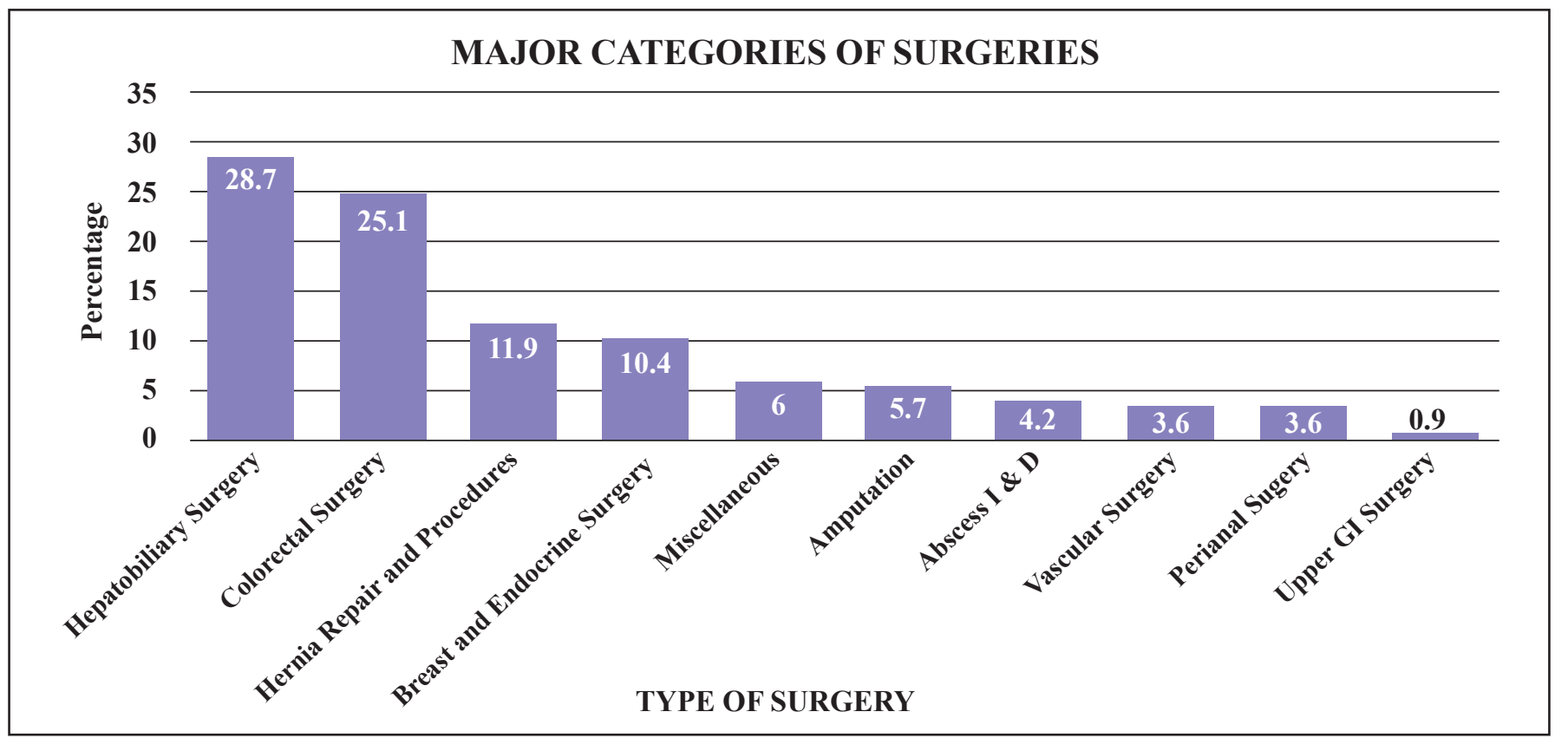

Fig. (2). Showing Percentage of Planned Procedures Done during the Course of Study which are Categorized into Major Surgeries.

All of the parameters of STOP-bang questionnaire including age $(p<0.001)$, gender $(p=0.026)$, BMI $(p<0.001)$, snoring $(\mathrm{p}<0.001)$, tiredness $(\mathrm{p}<0.001)$, sleep apnea $(\mathrm{p}=0.001)$, diastolic blood pressure $(\mathrm{p}<0.001)$ and neck circumference $(p<0.001)$ were significantly different between high risk and low risk patients with significantly higher frequency of high risk patients belonging to age group $\geq 50$ years $(66.7 \%)$, males gender $(51.9 \%)$, BMI of $\geq 35 \mathrm{~kg} / \mathrm{m} 2(19.3 \%)$, snoring group (51.1\%), having tiredness $(65.2 \%)$, had sleep apnea $(17 \%)$, diastolic BP of $\geq 90 \mathrm{mmHg}(56.3 \%)$, neck circumference of $\geq$ $40 \mathrm{~cm}(40 \%)$ than patients who belonged to low risk group in Table 2.

Table. 2. Association of Factors with the Risk of Severe Obstructive Sleep Apnea.

\begin{tabular}{|l|c|c|c|}
\hline \multicolumn{1}{|c|}{ STOP-BANG } & \multicolumn{2}{|c|}{ Risk } & P-value \\
\hline & $\begin{array}{c}\text { High n } \\
\text { (Percent) }\end{array}$ & $\begin{array}{c}\text { Low n } \\
\text { (Percent) }\end{array}$ & \\
\hline Age & $45(33.3)$ & $161(80.5)$ & \multirow{2}{*}{$<0.001^{*}$} \\
\hline$<50$ years & $90(66.7)$ & $39(19.5)$ & \\
\hline$\geq 50$ years &
\end{tabular}

\begin{tabular}{|c|c|c|c|}
\hline \multicolumn{4}{|l|}{ Gender } \\
\hline Male & $70(51.9)$ & 79(39.5) & \multirow{2}{*}{$0.026^{*}$} \\
\hline Female & $65(48.1)$ & $121(60.5)$ & \\
\hline \multicolumn{4}{|c|}{ Body Mass Index(BMI) } \\
\hline$<35 \mathrm{Kg} / \mathrm{m}^{2}$ & $109(80.7)$ & 199(99.5) & \multirow{2}{*}{$<0.001^{*}$} \\
\hline$\geq 35 \mathrm{Kg} / \mathrm{m}^{2}$ & $26(19.3)$ & $1(0.5)$ & \\
\hline \multicolumn{4}{|l|}{ Snoring } \\
\hline Yes & $69(51.1)$ & $20(10)$ & \multirow{2}{*}{$<0.001^{*}$} \\
\hline No & $66(48.9)$ & $180(90)$ & \\
\hline \multicolumn{4}{|l|}{ Tired } \\
\hline Yes & $88(65.2)$ & $69(34.5)$ & \multirow{2}{*}{$<0.001^{*}$} \\
\hline No & $47(34.8)$ & $131(65.5)$ & \\
\hline \multicolumn{4}{|c|}{ Sleep Apnea } \\
\hline Yes & $23(17)$ & $12(6)$ & \multirow{2}{*}{$0.001 *$} \\
\hline No & $112(83)$ & $188(94)$ & \\
\hline \multicolumn{4}{|c|}{ Diastolic Blood Pressure } \\
\hline$<90 \mathrm{mmHg}$ & $59(43.7)$ & $179(89.5)$ & \multirow{2}{*}{$<0.001^{*}$} \\
\hline$\geq 90 \mathrm{mmHg}$ & $76(56.3)$ & $21(10.5)$ & \\
\hline \multicolumn{4}{|c|}{ Neck Circumference } \\
\hline$<40 \mathrm{~cm}$ & $81(60)$ & $188(94)$ & \multirow{2}{*}{$<0.001 *$} \\
\hline$\geq 40 \mathrm{~cm}$ & $54(40)$ & $12(6)$ & \\
\hline
\end{tabular}

* Significant at $\mathrm{P}$-value $<0.05$ 


\section{DISCUSSION}

We found in our study that sleep apnea prevalence rate is higher in preoperative patients. It has negative predicted value of $93 \%$ to $100 \%$ [16] and it is developed by Chung, et al. [17]. Our results showed $40.3 \%$ of the Pakistan populations were of high risk which is consistent but lower than results by Kulkarni GV, et al. [16] which showed 64.6\%. In Kulkarni study, there was strong association with Male gender but no significant association found between age, weight, BMI and any other component of STOP-BANG questions but we found significant association between age, BMI, gender and all other components of STOP-BANG questions. Vasu, et al. [18] showed in his cohort study of elective surgical patients which had prevalence rate of $41 \%$ exactly same as our results of Pakistan population. There are some other studies which have taken $30 \mathrm{~kg} / \mathrm{m}^{2}$ as a YES index for STOP-BANG questionnaire while we took $35 \mathrm{~kg} / \mathrm{m}^{2}$, which could be the reason for variable results in different studies. BMI higher than $30 \mathrm{~kg} / \mathrm{m}^{2}$ shown higher sensitivity but lower specificity [16]. The factor of obesity is very important as one study evaluated the patients in bariatric surgery clinic which showed the prevalence rate of OSA in obese people is upto $70 \%$ [19].

The STOP-BANG questionnaire is easy to calculate and it take into account risk factors like obesity, age, circumference of neck, and male/female gender in addition to symptoms such as snoring and tiredness. This STOP-Bang questionnaire has sensitivity of $100 \%$ for patients with severe OSA and $96.2 \%$ sensitivity for moderate OSA [16]. Another factor worth noting is no one in our study underwent polysomnography test which is a limitation in our study. Young, et al. [1] observed $80 \%$ men and $90 \%$ women have OSA who were previously undiagnosed and showed that most sensitive and strongest predictor of sleep apnea is snoring. Kulkarni, et al. [16] also showed he had $19.3 \%$ of patients with high risk of OSA on STOP-BANG questionnaire and were diagnosed by PSG.

There is also high prevalence of comorbidities in severe OSA as shown by our study that $56 \%$ of patients of high risk OSA have been previously or being treated for raised blood pressure. Lattimore JD, et al. [6] shows that OSA and raised blood pressure are connected and that both have same risk factors. There is also high morbidity associated with OSA as observed by Marshall NS, et al. [8] in his study. He also showed that there is strong association between high risks of all-cause mortality with moderate-to-severe OSA. These findings shows that there is high risk of perioperative complications with patients with severe OSA.

It is very important to evaluate patients preoperatively for OSA. In a STOP-BANG questionnaire score of less than 3 has low risk but scores of 5-8 is highly predictive of moderate-to-severe OSA and requires immediate attention to further evaluate these patients for diagnosing with PSG test [18]. High risk patients should have been subjected to polysomnography test (PSG) to confirm high risk patients but no one underwent sleep study which is a limitation of this study. The American Society of Anesthesiologists guidelines from 2014 also stress that preoperative evaluation of patients is very important for any perioperative complications and to evaluate anything that can lead to perioperative complications as identifying the risk factors which were previously undiagnosed is the significant step to avoid any unwanted complication postoperatively [20].

The strength of our study rely on the sample that is representative of surgical patient population coming to a tertiary care clinic using a simple, reliable and valid tool. The limitation of our study is the fact that our sample neither had PSG done before nor underwent for PSG, limiting our study to quantify negative predicted value of questionnaire. This study did not look at perioperative complications related to OSA due to limitations of the study.

This study shows that if patients are diagnosed early and before surgery it can help by giving necessary treatment and streamlining the perioperative care [20]. This study can help improve the collaboration between surgeons, anesthetists and physicians to treat sleep apnea to get better postoperative outcomes of patients $[18,19]$. In our society the patients agree for any preoperative evaluation regarding OSA as long as it is a prerequisite for surgery but they will not get screen or get treated until it bothers them.

\section{CONCLUSION}

Obstructive Sleep Apnea (OSA) is not uncommon in surgical patients presenting in Opd. None of them undergo further evaluation in Pakistan. Further, inquest is needed to find out the impacts of preoperative diagnosis and treatment of OSA on postoperative care and complications.

\section{AUTHORS' CONTRIBUTION}

All authors have contributed equally.

\section{CONFLICT OF INTEREST}

Declared none.

\section{ACKNOWLEDGEMENTS}

Declared none.

\section{REFERENCES}

[1] Young T, Hutton R, Finn L, Badr S, Palta M. The gender bias in sleep apnea diagnosis: Are women missed because they have different symptoms? Arch Intern Med 1996; 156(21): 2445-51. DOI: $10.1001 /$ archinte.156.21.2445

[2] Patel SR. Obstructive sleep apnea. Ann Int Med 2019; 171(11): ITC81-ITC96. DOI: 10.7326/AITC201912030

[3] Kositanurit W, Muntham D, Udomsawaengsup S, Chirakalwasan N. Prevalence and associated factors of obstructive sleep apnea in morbidly obese patients undergoing bariatric surgery. Sleep Breath 2018; 22(1): 251-6. DOI: 


$$
\text { 10.1007/s11325-017-1500-y }
$$

[4] Chudeau N, Raveau T, Carlier L, et al. The STOP-BANG questionnaire and the risk of perioperative respiratory complications in urgent surgery patients: A prospective, observational study. Anaesth Crit Care Pain Med 2016; 35(5): 347-53. DOI: 10.1016/j.accpm.2016.01.006

[5] Sultan N, Ajmal M, Saqib IU, et al. Obstructive sleep apnoea in Pakistan: A single tertiary care center experience. Cureus 2019; 11(12): e6459. DOI: 10.7759/cureus.6459

[6] Lattimore JD, Celermajer DS, Wilcox I. Obstructive sleep apnea and cardiovascular disease. J Am Coll Cardiol 2003; 41(9): 1429-37. DOI: 10.1016/S0735-1097(03)00184-0

[7] Chung AS, DiGiovanni R, Tseng S, Hustedt JW, Chutkan N. Obstructive sleep apnea in elective spine surgery: National prevalence and inpatient outcomes. Global Spine J 2018; 8(6): 550-6. DOI: $10.1177 / 2192568217740898$

[8] Marshall NS, Wong KK, Liu PY, Cullen SR, Knuiman MW, Grunstein RR. Sleep apnea as an independent risk factor for all-cause mortality: The Busselton Health Study. Sleep 2008; 31(8): 1079-85.

[9] Kaw R, Chung F, Pasupuleti V, Mehta J, Gay P, Hernandez A. Meta-analysis of the association between obstructive sleep apnoea and postoperative outcome. Br J Anaesth 2012; 109(6): 897-906. DOI: 10.1093/bja/aes308

[10] Gross JB, Bachenberg KL, Benumof JL, et al. Practice guidelines for the perioperative management of patients with obstructive sleep apnea: A report by the American Society of Anesthesiologists Task Force on Perioperative Management of patients with obstructive sleep apnea. Anesthesiology 2006; 104(5): 1081-93; quiz 117-8.

DOI: $10.1097 / 00000542-200605000-00026$

[11] Marin JM, Carrizo SJ, Vicente E, Agusti AG. Long-term cardiovascular outcomes in men with obstructive sleep apnoea-hypopnoea with or without treatment with continuous positive airway pressure: An observational study. Lancet 2005; 365(9464): 1046-53. DOI: 10.1016/S0140-6736(05)71141-7
[12] Duran-Cantolla J, Aizpuru F, Martinez-Null C, Barbe-Illa F. Obstructive sleep apnea/hypopnea and systemic hypertension. Sleep Med Rev 2009; 13(5): 323-31. DOI: 10.1016/j.smrv.2008.11.001

[13] Tzischinsky O, Shahrabani S, Peled R. Factors affecting the decision to be treated with continuous positive airway pressure for obstructive sleep apnea syndrome. Isr Med Assoc J 2011; 13(7): 413.

[14] Chung F, Yegneswaran B, Liao P, et al. STOP questionnaire: A tool to screen patients for obstructive sleep apnea. Anesthesiology 2008; 108(5): 812-21.

DOI: 10.1097/ALN.0b013e31816d91b5

[15] The Evidence Report. Clinical guidelines on the identification, evaluation, and treatment of overweight and obesity in adults. Bethesda (MD): National Heart, Lung, and Blood Institute 1998; Report No.: 98-4083.

[16] Kulkarni GV, Horst A, Eberhardt JM, Kumar S, Sarker S. Obstructive sleep apnea in general surgery patients: is it more common than we think? Am J Surg 2014; 207(3): 436-40; discussion 9-40. DOI: 10.1016/j.amjsurg.2013.09.018

[17] Chung F, Subramanyam R, Liao P, Sasaki E, Shapiro C, Sun Y. High STOP-Bang score indicates a high probability of obstructive sleep apnoea. Br J Anaesth 2012; 108(5): 768-75. DOI: $10.1093 / \mathrm{bja} / \mathrm{aes} 022$

[18] Vasu TS, Doghramji K, Cavallazzi R, et al. Obstructive sleep apnea syndrome and postoperative complications: Clinical use of the STOP-BANG questionnaire. Arch Otolaryngology--Head Neck Surg 2010; 136(10): 1020-4. DOI: 10.1001/archoto. 2010.1020

[19] Frey WC, Pilcher J. Obstructive sleep-related breathing disorders in patients evaluated for bariatric surgery. Obesity Surg 2003; 13(5): 676-83.

DOI: $10.1381 / 096089203322509228$

[20] Memtsoudis SG, Besculides MC, Mazumdar M. A rude awakening--the perioperative sleep apnea epidemic. New Engl J Med 2013; 368(25): 2352-3. DOI: 10.1056/NEJMp1302941 